\title{
Characterization of Volatile Compounds in Four Different Rhododendron Flowers by GCXGC-QTOFMS
}

\author{
Chen-Yu Qian ${ }^{1,2}$, Wen-Xuan Quan ${ }^{2} \mathbb{C}$, Zhang-Min Xiang ${ }^{1, *} \mathbb{C}$ and Chao-Chan $\mathrm{Li}^{2, *} \mathbb{C}$ \\ 1 Guangdong Provincial Key Laboratory of Emergency Test for Dangerous Chemicals/Guangdong \\ Engineering and Technology Research Center for Ambient Mass Spectrometry, Guangdong Institute of \\ Analysis, Guangzhou 510070, China; qianchenyu94@163.com \\ 2 Guizhou Provincial Key Laboratory of Mountainous Environmental Protection, Guizhou Normal University, \\ Guiyang 550001, China; wenxuanq@gznu.edu.cn \\ * Correspondence: xiangzm@live.com (Z.-M.X.); chaochanl@gznu.edu.cn (C.-C.L.)
}

Academic Editor: Igor Jerković

Received: 14 August 2019; Accepted: 11 September 2019; Published: 12 September 2019

\begin{abstract}
Volatile compounds in flowers of Rhododendron delavayi, R. agastum, R. annae, and R. irroratum were analyzed using comprehensive two-dimensional gas chromatography-mass spectrometry (GC $\times$ GC) coupled with high-resolution quadrupole time-of-flight mass spectrometry (QTOFMS). A significantly increased number of compounds was separated by $\mathrm{GC} \times \mathrm{GC}$ compared to conventional one-dimensional GC (1DGC), allowing more comprehensive understanding of the volatile composition of Rhododendron flowers. In total, 129 volatile compounds were detected and quantified. Among them, hexanal, limonene, benzeneacetaldehyde, 2-nonen-1-ol, phenylethyl alcohol, citronellal, isopulegol, 3,5-dimethoxytoluene, and pyridine are the main compounds with different content levels in all flower samples. 1,2,3-trimethoxy-5-methyl-benzene exhibits significantly higher content in $R$. irroratum compared to in the other three species, while isopulegol is only found in $R$. irroratum and R. agastum.
\end{abstract}

Keywords: Rhododendron flowers; volatile compounds; comprehensive two-dimensional gas chromatography-mass spectrometry; quadrupole time-of-flight mass spectrometry; odor description

\section{Introduction}

The evergreen woody shrub genus Rhododendron is one of the largest genera in the family Ericaceae, and more than 1000 species are currently recognized; of these, 567 species representing 6 subgenera are known from China [1,2]. Rhododendrons are not only of high ornamental value but also good medicinal plants. Flowers of Rhododendron provide a large number of bioactive natural chemical products, including diterpenoids [3], flavonoids [4], and phenols [5], which are known to be effective for the treatment of rheumatism [6] and to have anti-inflammatory [7], anti-cancer [8], and antioxidant [9] properties. Volatile compounds from flowers also provide some ecological functions [10], including in the role of pollinators [11] and as defenders against nectar-thieving ants [12]. Aside from their ecological functions, flower volatiles have some aesthetic and emotional benefits for humans [13]. On the other hand, different volatile compounds may influence the odor, both in an individual and in a synergistic or antagonistic way, which in turn could be related to one or more chemical compounds or compound classes [14]. In order to investigate the aroma characteristics of Rhododendron flowers, it is important to research specific volatile constituents as thoroughly as possible. Rhododendron irroratum, R. delavayi, R. annae, and R. agastum are ecologically and horticulturally important alpine flowers and are also the pioneer and constructive species in Baili Rhododendron National Forest Reserve in the Guizhou province of China [15]. R. delavayi belongs to the subsection Arborea, while R. irroratum, 
R. annae, and R. agastum belong to the subsection Irrorata. R. irroratum is one of the large-flowered Rhododendron species [16]. These species were chosen for the investigation of volatile odor constituents in different Rhododendron flowers.

Gas chromatography-mass spectrometry (GC-MS) has long been the primary technique used to detect the aroma components of various plants $[17,18]$. However, GC-MS can only identify a limited number of separable compounds due to its insufficient peak capacity, limited resolved power, and low sensitivity [19]. The combination of gas chromatography with high-resolution quadrupole time-of-flight mass spectrometry (QTOFMS) has been demonstrated for analysis in different fields, including flavor research [20] and volatile profiling [21], and has proved to be a powerful analytical tool. However, the limited chromatographic separation power inevitably causes co-elution problems for complex samples. Compared with traditional one-dimensional gas chromatography (1DGC), comprehensive two-dimensional gas chromatography (GC $\times \mathrm{GC})$, which has appeared as a new analytical technique based on the application of two GC columns with different stationary phases, provides substantially enhanced resolving power and peak capacity. GC $\times$ GC leads to linear distributions of homologous series in 2D chromatograms, thus greatly reducing the coelution problem [22]. GC $\times$ GC can thus be a more suitable tool for analysis of the complex chemical systems of plant aroma, where the number of volatile aroma compounds is large and some of them are present at trace levels [23]. Recently, GC $\times$ GC technology has been successfully applied for the assessment of various plants such as teas [24], berries [25], and tobacco [26]. To date, few reports have studied the volatile chemical components in Rhododendron flowers by 1DGC. With the 1DGC technique, 9,12,15-octadecatrienoic acid,[Z,Z,Z]-, phytol, and $n$-hexadecanoic acid were found to be the major compounds in flowers of $R$. mucronatum and $R$. simii [27]; while R. ponticum comprises mostly $\alpha$-pinene, $\beta$-pinene, and linalool [28], in flowers of $R$. schlippenbachii, only 39 hydrophilic compounds could be detected by 1DGC [29]. A previous study reported the volatile compounds in the leaves, stems, and roots of six Rhododendron species [15]. However, the volatile components in flowers of the four Rhododendron species in the present study have never been investigated by the GC $\times$ GC approach before. Therefore, it is necessary to study the flowers' volatile compounds in order to explore odor characterizations.

In this study, GCXGC-QTOFMS was used in combination with headspace solid-phase microextraction (HS-SPME) to conduct in-depth analysis of the volatile aroma constituents in different Rhododendron flowers. The advantages of GC×GC-QTOFMS were exploited for high-throughput, untargeted chromatographic profiling of complex samples. The volatile compounds and their corresponding contents in various representative Rhododendron samples were examined. The obtained results provide useful information for establishing a volatile aroma chemical database from Rhododendron flowers.

\section{Results and Discussion}

\subsection{Comparison of $1 D G C$ and $G C \times G C$}

In typical 1DGC analysis, it is often difficult to achieve pure mass spectra for compounds in a co-elution peak, thus leading to unreliable results. With improved separation power and enhanced sensitivity, the GC $\times$ GC technique is able to resolve and detect more volatile aroma compounds in a complex sample compared to conventional one-dimensional GC-MS [30]. A clear illustration demonstrating the employment of $\mathrm{GC} \times \mathrm{GC}$ is presented in Figure 1. Both the chromatogram obtained by GC $\times$ GC-TOF/MS using a $4 \mathrm{~s}$ modulation period and the total ion chromatography by 1DGC are shown. As can be seen in the partial chromatograms obtained by 1DGC and GC $\times$ GC-QTOFMS, linalool $\left(\right.$ Peak $\left.1,{ }^{1} t_{\mathrm{R}}=19.783 \mathrm{~min},{ }^{2} t_{\mathrm{R}}=1.405 \mathrm{~s}\right)$ and 2-nonen-1-ol (Peak $\left.2,{ }^{1} t_{\mathrm{R}}=19.849 \mathrm{~min},{ }^{2} t_{\mathrm{R}}=1.447 \mathrm{~s}\right)$ were responsible for the two peaks detected between retention times of $19.380 \mathrm{~min}$ and $19.850 \mathrm{~min}$ on the HP-5 MS column. However, three other minor compounds in addition to these two peaks were further separated as they exhibited different polarities on the DB-17 MS column; these were linalool oxide (Peak $\left.3,{ }^{1} t_{\mathrm{R}}=19.383 \mathrm{~min},{ }^{2} t_{\mathrm{R}}=1.467 \mathrm{~s}\right), p$-cymenene (Peak $\left.4,{ }^{1} t_{\mathrm{R}}=19.450 \mathrm{~min},{ }^{2} t_{\mathrm{R}}=1.627 \mathrm{~s}\right)$, 
and benzoic acid, methyl ester (Peak $5,{ }^{1} t_{\mathrm{R}}=19.716 \mathrm{~min},{ }^{2} t_{\mathrm{R}}=2.017 \mathrm{~s}$ ). The co-eluted compounds in the peak region were interfered with by dominating compounds and would usually be ignored due to their low concentrations. In summary, GC $\times$ GC successfully resolved a total of 129 compounds, while only 45 compounds were separated in 1DGC (Table S1). The results revealed the great advantages of GC $\times$ GC analysis, which is suitable for the investigation of volatile compounds in complex samples.

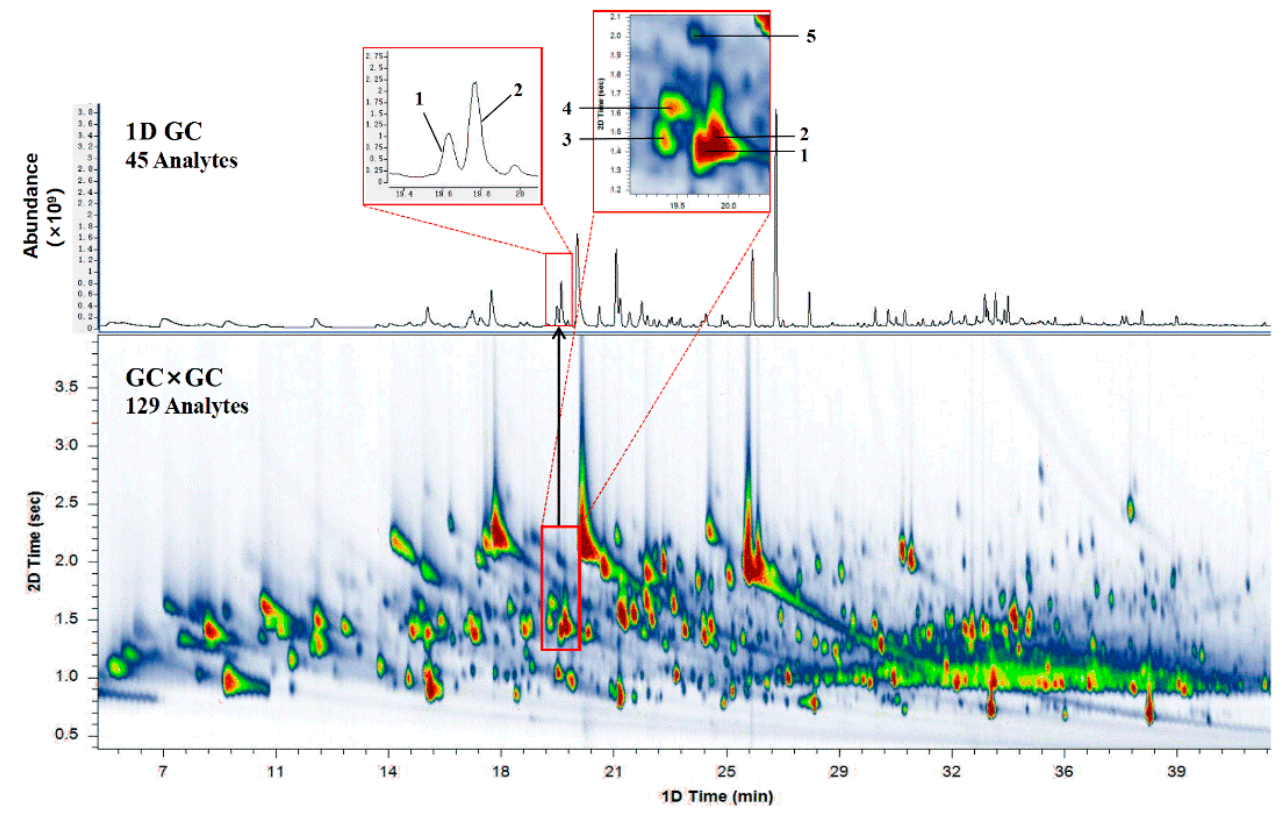

Figure 1. Chromatographic analysis of Rhododendron by GC-quadrupole time-of-flight mass spectrometry (QTOFMS) and a comprehensive two-dimensional gas chromatography-mass spectrometry (GC×GC)-QTOFMS color diagram (1: linalool; 2: 2-nonen-1-ol; 3: linalool oxide; 4: $p$-cymenene; 5: benzoic acid, methyl ester).

\subsection{Identification of Common Volatile Components}

GC $\times$ GC-QTOFMS was used to characterize the detailed chemical composition of all the samples. Several hundred peaks were generated in the GC $\times$ GC contour plot with a peak detection threshold of $\mathrm{S} / \mathrm{N}>3$. In total, 129 volatile compounds were tentatively identified in four Rhododendron samples based on (1) spectral similarity (both match and reverse match scores of $>750$ ), (2) comparison with molecular ions (within 5 ppm), if they existed, and (3) retention index (RI, \pm 35 ). Table S1 lists the complete information of the 129 volatile constituents detected by GCXGC-QTOFMS.

Figure 2 introduces the identification process of two examples (1,2-dimethoxybenzene and lilac aldehyde D). First, the National Insititute of Standards and Technology (NIST) library search for Peak 162 and Peak 189 resulted in 7 and 5 possible compounds, respectively, with match factor $>750$. Then, only exact mass analyses within a mass accuracy of $<5 \mathrm{ppm}$ were considered. For Peak 162, the measured accurate mass was 138.0676, which corresponds to a formula of $\mathrm{C}_{8} \mathrm{H}_{10} \mathrm{O}_{2}$. The accurate mass reduced the number of possible compounds to two isomers (1,2-dimethoxybenzene and 1,4-dimethoxybenzene). Last, their retention indices were reviewed for further confirmation. The GC $\times$ GC analysis provided an experimental RI value of 1151 for this peak, which matched 1,2-dimethoxybenzene (literature RI value of 1151) rather than 1,4-dimethoxybenzene $\left(\mathrm{RI}_{\text {lit }}=1168\right)$. Therefore 1,2-dimethoxybenzene was the final identified compound for Peak 162.

Taking Peak 189 as another example: The NIST library search provided several possible compound matches. Among them, seven possible compounds were screened out according to their relatively high match scores. Subsequently, the mass spectrum provided a measured mass of 168.1148, corresponding to a chemical formula of $\mathrm{C}_{10} \mathrm{H}_{16} \mathrm{O}_{2}$. This indicated that 2-methyl-2-(2-oxopropyl) cyclohexanone, lilac aldehyde $\mathrm{D}$, and 2-hydroxy-4,4,6,6-tetramethyl-2- cyclohexen-1-one were three 
possible compounds with the theoretical molecular ion mass of 168.1145. Lastly, the experimental RI value of the peak $\left(\mathrm{RI}_{\exp }=1190\right)$ confirmed that lilac aldehyde $\mathrm{D}$ with $\mathrm{RI}_{\mathrm{lit}}$ of 1169 was the final identified compound for Peak 189, while the other two candidates, 2-methyl-2-(2-oxopropyl) cyclohexanone $\left(\mathrm{RI}_{\text {lit }}=1360\right)$ and 2-hydroxy-4,4,6,6-tetramethyl-2-cyclohexen-1-one $\left(\mathrm{RI}_{\text {lit }}=1272\right)$, were screened out. The results emphasis the importance of applying further confirmation on the base of the spectral library match, since the compound with the highest match factor might be mistaken for the identity of the component [31]. In conclusion, with complementary identification processes, GC $\times$ GC coupled with high-resolution QTOFMS produces more precise compound identification results.
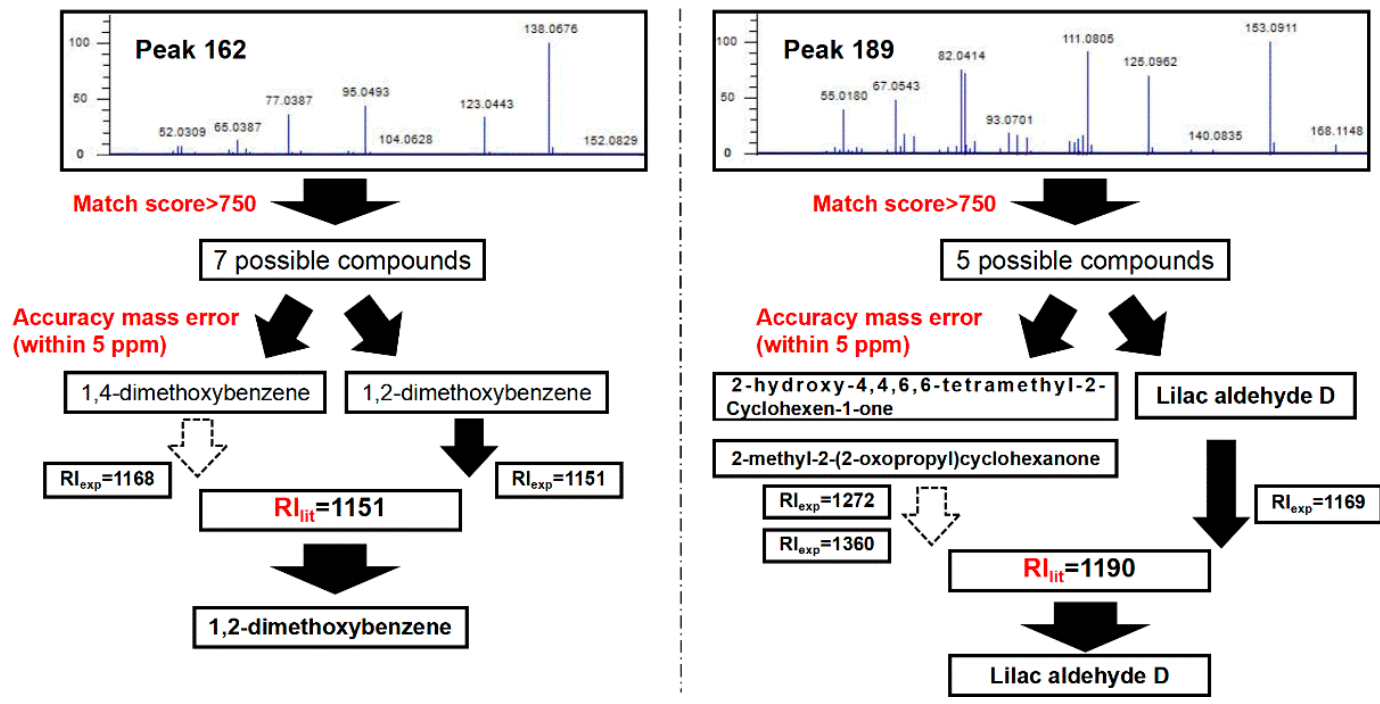

Figure 2. Diagram illustrating the process of compound confirmation in GCXGC-QTOFMS.

\subsection{Volatile Component Analysis}

In order to establish the experimental conditions, the mixed sample was analyzed via GC $\times$ GC-QTOFMS in triplicate. The intraday precision was evaluated by analyzing three equivalent mixed samples on the same day, and this was then repeated for three consecutive days to determine the interday precision. As shown in Table S2, the intraday and interday precision were expressed as the relative standard deviation (RSD). RSD values of no more than $25 \%$ were found in each compound in the mixed sample, demonstrating the good repeatability of the GCXGC-QTOFMS method. Subsequently, the four flower species were analyzed by the established method. The relative contents (\%) of compounds in each sample were calculated based on the ratio of the area of the corresponding peak to the total peak area; the averages of the relative contents of each compound in the Rhododendron flower samples are tabulated in Table S2. Figure 3 presents the distribution (\%) of the major compounds in the four different species of Rhododendron. Among them, benzeneacetaldehyde was found in all flower species with high content in $R$. irroratum $(6.255 \% \pm 0.951 \%), R$. delavayi $(7.013 \% \pm 0.059 \%)$, and R. annae $(6.349 \% \pm 0.062 \%)$, whereas it presented with relatively low content in $R$. agastum $(2.987 \% \pm 0.357 \%)$. Citronellal presented the highest content in $R$. annae $(7.004 \% \pm 0.028 \%)$ and $R$. agastum $(7.722 \% \pm$ $0.303 \%)$, and was the second most abundant component in $R$. delavayi $(7.944 \% \pm 0.225 \%)$, but was slightly low in R. irroratum $(4.178 \% \pm 0.654 \%)$. Both benzeneacetaldehyde and citronellal contribute to the sweet floral profile of these samples. Benzeneacetaldehyde has a grassy odor, while citronellal has a slight hyacinth odor. 1,2,3-trimethoxy-5-methyl-benzene was detected in all species with content ranging from trace $(0.243 \% \pm 0.023 \%$ in $R$. annae $)$ to abundant $(6.046 \% \pm 0.623 \%$ in $R$. irroratum). On the other hand, isopulegol was detected only in R. irroratum and R. agastum, with a highest content of 7.722\% $\pm 0.407 \%$ in $R$. agastum. Thus, this compound can be used to discriminate R. agastum or R. irroratum from other Rhododendron species. Phenylethyl alcohol accounted for a significantly high content in R. delavayi (up to $8.922 \% \pm 0.061 \%$ ) compared to in the other three species and was characterized 
as a dried rose floral aroma. Similarly, 2-nonen-1-ol, with a sweet melon odor, also presented the highest content in $R$. delavayi $(5.633 \% \pm 0.813 \%)$ but slightly low in $R$. irroratum $(4.299 \% \pm 0.288 \%)$ and $R$. agastum $(4.071 \% \pm 0.378 \%)$. Limonene and isopulegol presented in all species with relatively low content compared with other major compounds and with no significant differences between species. Limonene has a sweet citrus or orange odor, while isopulegol has a minty or woody odor. Although the rest of the compounds had relatively low threshold values due to their low contents, they all play a certain role in the odor characterization and finally form the special odor types of different Rhododendron varieties.

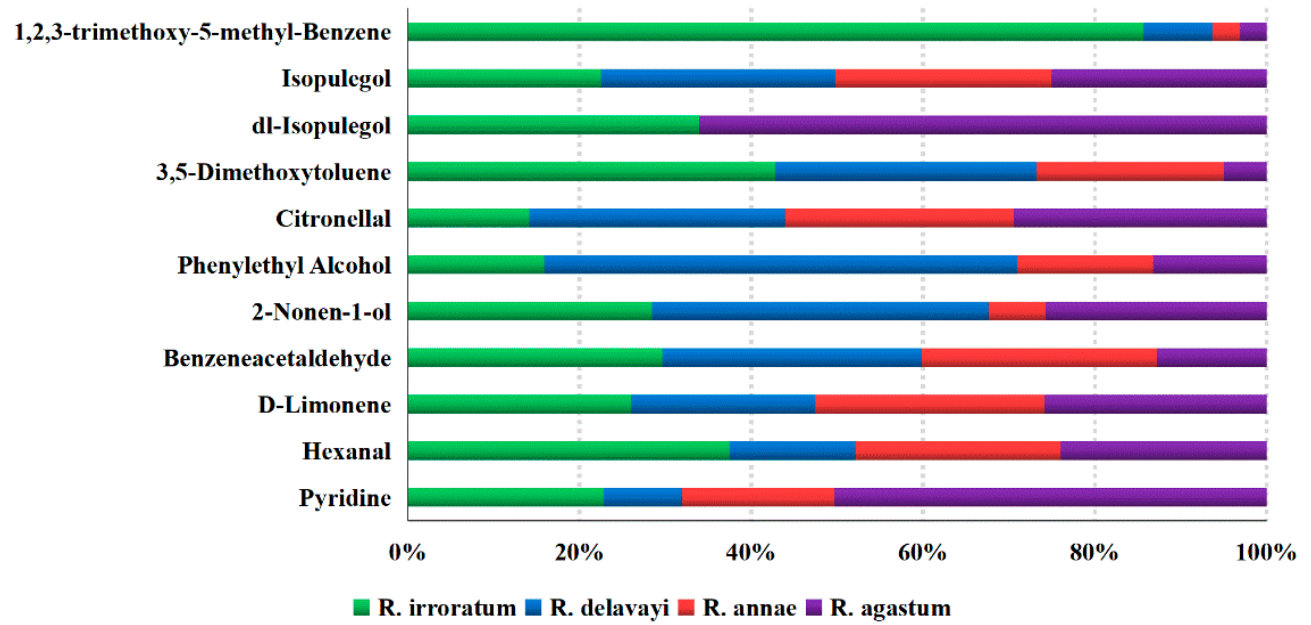

Figure 3. Distribution (\%) of major compounds presented in four different species of Rhododendron.

\subsection{Odor Analysis}

The identified components were classified into various types of compound groups, including alcohols (29), aldehydes (15), alkenes (29), aromatic hydrocarbons (10), esters (19), ketones (10), phenols (4), and others (13) - eight classes in total. Figure 4 shows the relative contents of the chemical classes in the four samples. The predominant groups were aldehydes and alcohols, followed by esters and alkenes. Large amounts of aldehydes were detected in R. annae (27.37\%) and R. irroratum (26.95\%). Although alkenes had the same number of compounds compared to alcohols, their contents were far below those of alcohols. Besides this, R. irroratum had the lowest content of esters $(6.04 \%)$, while the other three species had similar proportions.

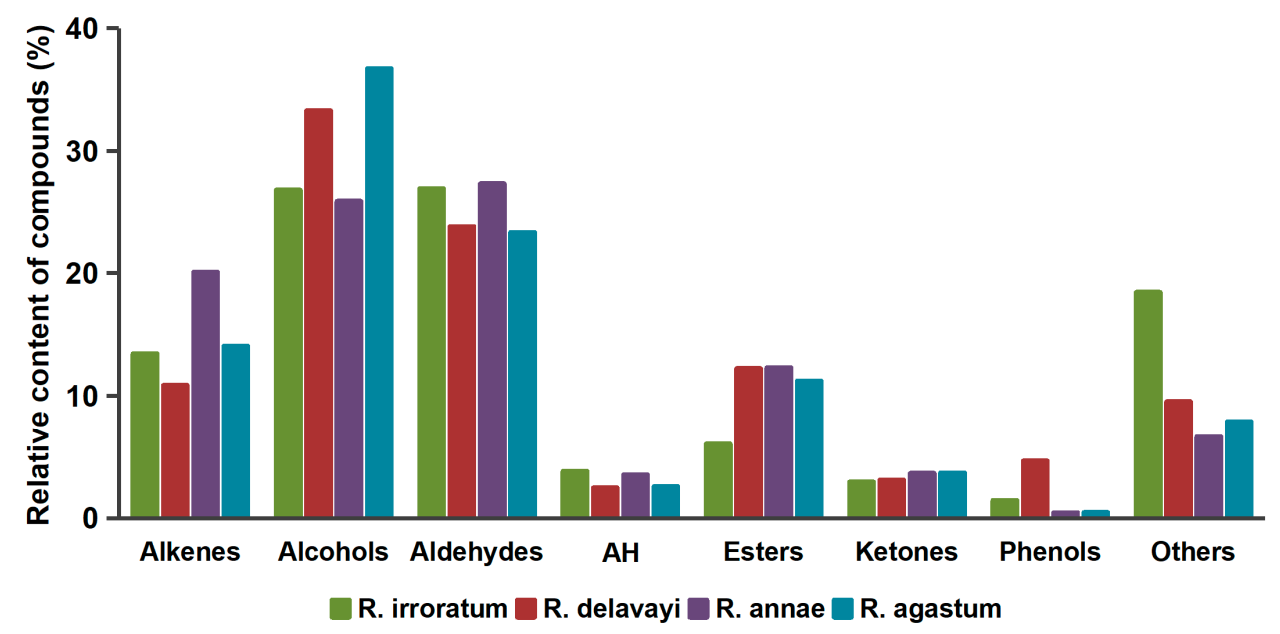

Figure 4. Distribution of the chemical classes for Rhododendron (AH: aromatic hydrocarbons). 


\subsubsection{Floral and Woody Odor}

From an odor perspective, alcohols showed a higher number of compounds with a descriptor of a floral odor. For example, linalool, which is reported to possess a floral and citrus-like aroma [32], was relatively high in the $R$. annae species $(4.752 \% \pm 0.114 \%)$. Aside from linalool, benzyl alcohol, phenylethyl alcohol, and citronellol are all described as having floral and rose odors. Among them, phenylethyl alcohol is widely used as ingredient for perfumes and produces a rose smell [33]. Citronellol was previously reported as the floral odor compound in lychee juice [34]. Woody odor attributes in Rhododendron flowers were mainly associated with alkenes and alcohols. Alkenes showed a higher number of compounds with descriptors of woody and sweet, such as $\alpha$-pinene (intense woody), $\beta$-pinene (dry woody), and $\alpha$-terpinene (woody, piney), which were previously identified in terebinth fruits [17], but accounted for relatively low contents $(0.117 \% \pm 0.056 \%$ to $1.456 \% \pm 0.039 \%)$ in flowers. Alcohols such as isopulegol and isoborneol also have woody odor characterization and accounted for $1.099 \% \pm 0.091 \%$ to $3.328 \% \pm 0.133 \%$ in Rhododendron flowers, mostly higher than the alkene contents. In addition, $\beta$-ionone, well known for its violet odor and described as a complex woody and fruity scent [35], was also found in four flower species.

\subsubsection{Green and Fresh Odor}

Grass odor is sometimes referred to as a fresh note, and the chemicals with this descriptor are predominantly aldehydes with six to nine carbons and C6 alcohols [36,37]. In Rhododendron flowers, hexanal was the major such compound in all samples, mainly contributing to the green and grassy odor. Besides this, 2-hexenal, heptanal, octanal, and benzeneacetaldehyde was also found to contribute to the green and fresh odor [34]. Among them, 2-hexenal and heptanal accounted for relatively high proportions in R. annae and R. agastum. On the other hand, C6 alcohols such as (E)-3-hexen-1-ol and 1 -hexanol also yielded a green, fresh, and herbal odor [32]. In addition, $\beta$-cadinene, 2-pentyl-furan and formic acid, 2-phenylethyl ester are also related to a green odor.

\subsubsection{Sweet and Fruity Odor}

In the Rhododendron flowers, the compounds contributing to the sweet and fruity odor mainly included aldehydes and alkenes. Among the aldehydes, citronellal (sweet, citrus), decanal (sweet, orange), and undecanal (floral, citrus) all provide a sweet and fruity odor, especially citronellal with its high contents in the four flower species $(4.178 \% \pm 0.654 \%$ to $7.944 \% \pm 0.225 \%)$. Among the alkenes, limonene is a typical sweet and citrus-like odor compound which was previously identified in lychee [32]. $\alpha$-Ocimene with a fruity aroma was also reported in a previous study [17]. Some alcohols like major compound 2-nonen-1-ol also have a sweet and melon odor. Besides this, it has been previously reported that $\alpha$-terpineol is one of the major components providing fruity and floral notes in Pu-erh tea [38]. Other compounds, for example, 2-pentyl-furan, reported to have a fruity, green, and earthy odor [39], accounted for a relatively high proportion in R. irroratum (up to $1.643 \% \pm 0.290 \%$ ) among the four flower species studied.

\subsubsection{Total Odor Description}

As illustrated by the four pie charts shown in Figure 5, the proportion distributions of volatile compounds based on the specific odor characteristics of the Rhododendron flowers were surveyed to represent the odor types of compounds in the samples. There was a higher number of chemical compounds with descriptors of floral, woody, sweet, and fresh odor, mainly derived from alkenes, alcohols, esters, and aldehydes, thus comprising the major odor characteristics of Rhododendron flowers. Sweet odor represented the highest proportion in R. annae (35.96\%), R. irroratum $(27.01 \%)$, and R. agastum $(31.46 \%)$, while floral odor was the most abundant in $R$. delavayi (up to $34.29 \%$ ). Other odors such as herbaceous, piney, and mushroom had relatively low proportions but also contributed to the overall odor characteristics. The different compounds and contents make up the specific Rhododendron 
odors. Volatile aroma components from various species and their content differences determine the flower-specific scent properties. Their odor values and contributions to flower odorant will be further investigated in the future.
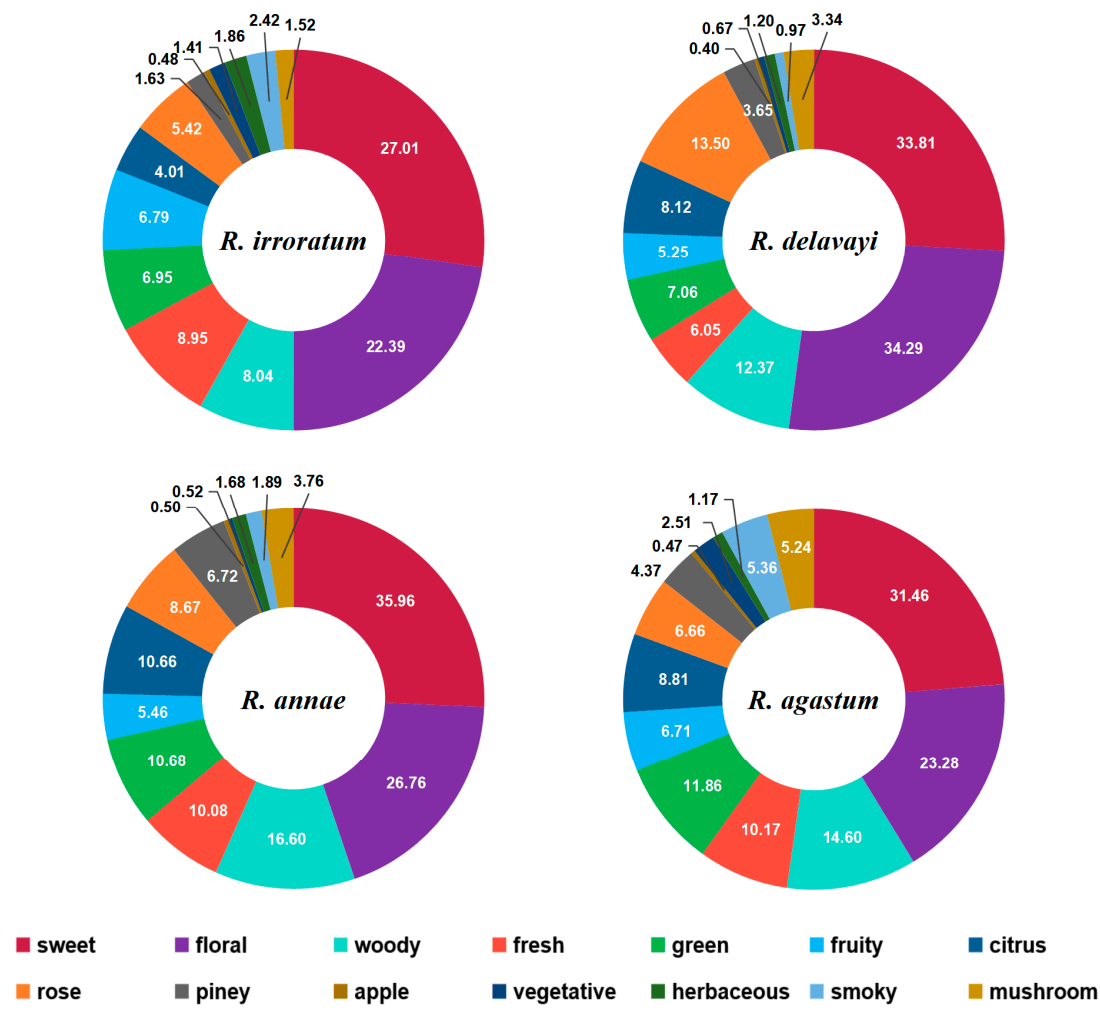

Figure 5. Proportions of odor compounds in Rhododendron.

\section{Materials and Methods}

\subsection{Sample Pretreatment}

The flowers from four Rhododendron species (R. delavayi, R. agastum, R. annae, and R. irroratum) were collected in the spring of 2019 (between March and April) in Baili Rhododendron National Forest

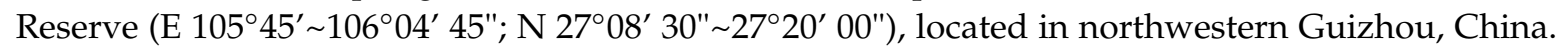
Flowers were collected and placed in sealed plastic bags, then immediately transported in a cooler with ice to the laboratory. Subsequently, the obtained samples were smashed after being frozen in a vacuum freeze-dryer for a week at $-70^{\circ} \mathrm{C}$ (FD-1C-80; Boyikang, Beijing, China), then transferred into $50 \mathrm{~mL}$ vials [15]. All samples were stored in a freezer at a temperature below $-20{ }^{\circ} \mathrm{C}$ until analysis. A mixed sample was prepared using all the four flower species in equal quantities and was used for analytical method establishment and repeatability examination.

\subsection{SPME Methodology}

The extraction and concentration of the volatile compounds were carried out using the headspace solid phase microextraction (HS-SPME) technique. As the object of this study was to characterize all volatile compounds, divinylbenzene/carboxen/polydimethylsiloxane (DVB/CAR/PDMS) fiber $(50 / 30 \mu \mathrm{m})$ (Supelco, Bellefonte, PA, USA) combining the characteristics of both carboxen and divinylbenzene adsorbents in the coating and thus allowing a wide range of molecules of different sizes to be adsorbed into the coating for natural products [40], was chosen for volatile compound analysis. Quantities of $50 \mathrm{mg}$ of samples were accurately weighed into a $20 \mathrm{~mL}$ vial, and then the SPME fiber was exposed to the headspace of the bottle for $20 \mathrm{~min}$ at $70^{\circ} \mathrm{C}$. The SPME fiber was then introduced into the GC injector for $3.0 \mathrm{~min}$ to allow thermal desorption of the analytes. The established 
approach for quantitative analysis was validated by studying the repeatability using the mixed sample. All measurements were conducted in triplicate.

\subsection{Analytical Instrumentation}

The system was equipped with simultaneous 1DGC and GC $\times$ GC in one instrument which can conduct both techniques at the same time without any change of columns. The system consisted of a gas chromatograph (7890B Agilent Technology, Santa Clara, CA, USA) coupled with a high-resolution quadrupole time-of-flight mass spectrometer (QTOFMS) (mass resolution 20,000 and a mass accuracy specification of 3 ppm) (7250, Agilent Technology). In the presented research, an HP-5 MS (5\% phenyl-95\% dimethylpolysiloxane, $30 \mathrm{~m} \times 250 \mu \mathrm{m}, 0.25 \mu \mathrm{m}$ film) was used as the ${ }^{1} \mathrm{D}$ column, and a DB-17 MS column (50\% phenyl-50\% dimethylpolysiloxane, $1.2 \mathrm{~m} \times 180 \mu \mathrm{m}, 0.18 \mu \mathrm{m}$ film) was used as the ${ }^{2} \mathrm{D}$ column. The samples were introduced by a split/splitless injector (SSL) system with an autosampler (PAL RSI 120, CTC Technologies). This study employed a technique to combine GC $\times$ GC and 1DGC components into a single system with the column outlet of each component connected at the same three-port splitter prior to the QTOFMS detection. This allowed direct comparison of the GC $\times$ GC and 1DGC results and avoided use of a second detector, which is simple and effective.

The 1DGC and GC $\times$ GC conditions were the same and were as listed below: the GC injector was kept at $250{ }^{\circ} \mathrm{C}$ in splitless mode; helium (99.999\%) was used as the carrier gas at a constant flow of $1.2 \mathrm{~mL} / \mathrm{min}$; oven temperature was initially set at $50{ }^{\circ} \mathrm{C}$ (held for $3 \mathrm{~min}$ ), then increased to $250{ }^{\circ} \mathrm{C}$ at $4{ }^{\circ} \mathrm{C} / \mathrm{min}$ (held for $7 \mathrm{~min}$ ), for a total run time of $60 \mathrm{~min}$. The GC $\times \mathrm{GC}$ system was coupled with an SSM1800 solid state modulator (J\&X Technologies, China). The GC $\times$ GC conditions were as follows: The cold zone temperature of the SSM was set at $-50{ }^{\circ} \mathrm{C}$. The temperatures of the entry hot zone and exit hot zone were +30 and $+120^{\circ} \mathrm{C}$ offset relative to oven temperatures, respectively, with a cap temperature of $320^{\circ} \mathrm{C}$ for both hot zones. The modulation period was $4 \mathrm{~s}$.

The MS conditions were as follows: The electron ionization and the ion source and transfer line temperatures were set at $70 \mathrm{eV}, 250^{\circ} \mathrm{C}$, and $280{ }^{\circ} \mathrm{C}$, respectively. The MS scan rate was $50 \mathrm{~Hz}$. The mass range was set to $50-500 \mathrm{~m} / \mathrm{z}$ in full-scan acquisition mode.

\subsection{Data Method}

The volatile composition was quantified in duplicate by HS-SPME coupled to GC $\times$ GC with QTOFMS according to the method of previous reports [41]. The 1DGC data were processed using Agilent Mass Hunter Qualitative Analysis navigator B.08.00; the GC $\times$ GC data were analyzed using dedicated Canvas GC $\times$ GC data processing software (J\&X Technologies, version v1.4.0, Shanghai, China). Tentative compound identification was accomplished by mass spectral match based on the NIST 17 Mass Spectral Library (NIST/EPA/NIH 2017) and then verified using the retention index (RI) and accurate mass. The RI was calculated using a series of $n$-alkanes (C8-C25) analyzed on an HP-5 MS column under the same chromatographic conditions. The odor identification method was performed based on previous studies [42], relying on the Good Scents Company Information System, available online: http://www.thegoodscentscompany.com.

\section{Conclusions}

GC $\times$ GC-QTOFMS was applied to identify the volatile aroma compounds in four Rhododendron flower species. In total, 129 volatile compounds were separated and confirmed by spectral similarity, exact mass, and retention index. The relative contents of the volatile compounds were profiled for the four species of Rhododendron flowers. With the great advantages of the GC $\times$ GC technique over traditional 1DGC, this preliminary study improved scientific understanding regarding the volatile components in Rhododendron flowers, and the detected compounds could be used to establish the fingerprint signatures of Rhododendron. 
Supplementary Materials: The following are available online at http://www.mdpi.com/1420-3049/24/18/3327/s1, Table S1. Complete compound information for identification; Table S2. Compound contents in Rhododendron flowers of different species and their odor description.

Author Contributions: Conceptualization, Z.M.X.; Methodology, C.-Y.Q.; Data curation: C.-Y.Q.; Supervision, W.-X.Q.; Writing—original draft preparation, C.-Y.Q.; Writing—review and editing, C.-C.L.

Funding: This study was supported by the GDAS' Project of Science and Technology Development (No. 2019GDASYL-0302004, 2018GDASCX-0808 and 2017GDASCX-0104), the National Natural Science Foundation of China (NSFC, No. 31960312), and Joint Fund of the National Natural Science Foundation of China and the Karst Science Research Center of Guizhou province (Grant No. U1812401), the Provincial Natural Science Foundation of Guizhou (Grant No. QKZYD [2017] 4006), special funds of industrial analysis and testing scientific research foundation and capacity in Guangdong province.

Conflicts of Interest: The authors declare no conflicts of interest.

\section{References}

1. Zhou, W.; Oh, J.; Li, W.; Kim, D.W.; Yang, M.H.; Jang, J.H.; Ahn, J.S.; Lee, S.H.; Na, M.K. Chemical constituents of the Korean endangered species Rhododendron Brachycarpum. Biochem. Syst. Ecol. 2014, 56, 231-236. [CrossRef]

2. Zhang, L.; Xu, P.W.; Cai, Y.F.; Ma, L.L.; Li, S.F.; Li, S.F.; Xie, W.J.; Song, J.; Peng, L.C.; Yan, H.J.; et al. The draft genome assembly of Rhododendron delavayi Franch. var. delavayi. GigaScience 2017, 6, 1-11. [CrossRef] [PubMed]

3. Zhou, S.Z.; Yao, S.; Tang, C.P.; Ke, C.Q.; Li, L.; Lin, G.; Ye, Y. Diterpenoids from the Flowers of Rhododendron Molle. J. Nat. Prod. 2014, 775, 1185-1192. [CrossRef]

4. Jung, S.J.; Kim, D.H.; Hong, Y.H.; Lee, J.H.; Song, H.N.; Rho, Y.D.; Baek, N.I. Flavonoids from the flower of Rhododendron yedoense var. Poukhanense and their antioxidant activities. Arch. Pharm. Res. 2007, 30, 146-150. [CrossRef] [PubMed]

5. Kiruba, S.; Mahesh, M.; Nisha, S.R.; Miller Paul, Z.; Jeeva, S. Phytochemical analysis of the flower extracts of Rhododendron arboreum Sm. ssp. nilagiricum (Zenker) Tagg. Asian Pac. J. Trop. Biomed. 2011, 1, S284-S286. [CrossRef]

6. Zhu, Y.X.; Zhang, Z.X.; Yan, H.M.; Lu, D.; Zhang, H.P.; Li, L.; Liu, Y.B.; Li, Y. Antinociceptive diterpenoids from the leaves and twigs of Rhododendron Decorum. J. Nat. Prod. 2018, 81, 1183-1192. [CrossRef] [PubMed]

7. Zhou, J.F.; Liu, T.T.; Zhang, H.Q.; Zheng, G.J.; Qiu, Y.; Deng, M.Y.; Zhang, C.; Yao, G.M. Anti-inflammatory grayanane diterpenoids from the leaves of Rhododendron molle. J. Nat. Prod. 2018, 81, 151-161. [CrossRef] [PubMed]

8. Wang, S.J.; Lin, S.; Zhu, C.G.; Yang, Y.C.; Li, S.; Zhang, J.J.; Chen, X.G.; Shi, J.G. Highly acylated diterpenoids with a New 3,4-Secograyanane Skeleton from the Flower Buds of $\backslash \mathrm{r}$ Rhododendron Molle. Org. Lett. 2010, 12, 1560-1563. [CrossRef]

9. Li, Y.; Liu, Y.B.; Yu, S.S. Grayanoids from the Ericaceae family: Structures, biological activities and mechanism of action. Phytochem. Rev. 2013, 12, 305-325. [CrossRef]

10. Zeng, L.T.; Wang, X.Q.; Dong, F.; Watanabe, N.; Yang, Z.Y. Increasing postharvest high-temperatures lead to increased volatile phenylpropanoids/benzenoids accumulation in cut rose (Rosa hybrida) flowers. Postharvest Biol. Tec. 2019, 148, 68-75. [CrossRef]

11. Pichersky, E.; Gershenzon, J. The formation and function of plant volatiles: Perfumes for pollinator attraction and defense. Curr. Opin. Plant. Biol. 2002, 5, 237-243. [CrossRef]

12. Junker, R.R.; Blüthgen, N. Floral scents repel potentially nectar-thieving ants. Evol. Ecol. Res. 2008, 10, 295-308.

13. Pichersky, E.; Dudareva, N. Scent engineering: Toward the goal of controlling how flowers smell. Trends Biotechnol. 2007, 25, 105-110. [CrossRef] [PubMed]

14. Kang, S.Y.; Yan, H.; Zhu, Y.; Liu, X.; Lv, H.P.; Zhang, Y.; Dai, W.D.; Guo, L.; Tan, J.F.; Peng, Q.H.; et al. Identification and quantification of key odorants in the world's four most famous black teas. Food Res. Int. 2019, 121, 73-83. [CrossRef]

15. Qian, C.Y.; Quan, W.X.; Li, C.C.; Xiang, Z.M. Analysis of volatile terpenoid compounds in Rhododendron species by multidimensional gas chromatography with quadrupole time-of-flight mass spectrometry. Microchem. J. 2019, 149, 104064. [CrossRef] 
16. Zha, H.G.; Milne, R.I.; Sun, H. Asymmetric hybridization in Rhododendron agastum: A hybrid taxon comprising mainly F1 s in Yunnan, China. Ann. Bot. 2010, 105, 89-100. [CrossRef] [PubMed]

17. Amanpour, A.; Guclu, G.; Kelebek, H.; Selli, S. Characterization of key aroma compounds in fresh and roasted terebinth fruits using aroma extract dilution analysis and GC-MS-Olfactometry. Microchem. J. 2019, 145, 96-104. [CrossRef]

18. Qia, D.D.; Miaoa, A.Q.; Cao, J.X.; Wang, W.W.; Chen, W.; Pang, S.; He, X.G.; Ma, C.Y. Study on the effects of rapid aging technology on the aroma quality of whitetea using GC-MS combined with chemometrics: In comparison with naturalaged and fresh white tea. Food Chem. 2018, 265, 189-199. [CrossRef] [PubMed]

19. Zhu, Y.; Lv, H.P.; Dai, W.D.; Guo, L.; Tan, J.F.; Zhang, Y.; Yu, F.L.; Shao, C.Y.; Peng, Q.H.; Lin, Z. Separation of aroma components in Xihu Longjing tea using simultaneous distillation extraction with comprehensive two-dimensional gas chromatography-time-of-flight mass spectrometry. Sep. Purif. Technol. 2016, 164, 146-154. [CrossRef]

20. Huang, X.H.; Zheng, X.; Chen, Z.H.; Zhang, Y.Y.; Du, M.; Dong, X.P.; Qin, L.; Zhu, B.W. Fresh and grilled eel volatile fingerprinting by e-Nose, GC-O, GC-MS and GC $\times$ GC-QTOF combined with purge and trap and solvent-assisted flavor evaporation. Food Res. Int. 2019, 115, 32-43. [CrossRef] [PubMed]

21. Liu, F.T.; Li, S.J.; Gao, J.H.; Cheng, K.; Yuan, F. Changes of terpenoids and other volatiles during alcoholic fermentation of blueberry wines made from two southern highbush cultivars. LWT 2019, 109, 233-240. [CrossRef]

22. Egert, B.; Weinert, C.H.; Kulling, S.E. A peaklet-based generic strategy for the untargeted analysis of comprehensive two-dimensional gas chromatography mass spectrometry data sets. J. Chromatogr. A. 2015, 1405, 168-177. [CrossRef] [PubMed]

23. Lukić, I.; Carlin, S.; Horvat, I.; Vrhovsek, U. Combined targeted and untargeted profiling of volatile aroma compounds with comprehensive two-dimensional gas chromatography for differentiation of virgin olive oils according to variety and geographical origin. Food Chem. 2019, 270, 403-414. [CrossRef] [PubMed]

24. Zhang, L.; Zeng, Z.D.; Zhao, C.X.; Kong, H.W.; Lu, X.; Xu, G.W. A comparative study of volatile components in green, oolong and black teas by using comprehensive two-dimensional gas chromatography-time-of-flight mass spectrometry and multivariate data analysis. J. Chromatogr. A. 2013, 1313, 245-252. [CrossRef] [PubMed]

25. Kupska, M.; Chmiel, T.; Jedrkiewicz, R.; Wardencki, W.; Namies'nik, J. Comprehensive two-dimensional gas chromatography for determination of the terpenes profile of blue honeysuckle berries. Food Chem. 2014, 152, 88-93. [CrossRef] [PubMed]

26. Schwanz, T.G.; Bokowski, L.V.V.; Marcelo, M.C.A.; Jandrey, A.C.; Dias, J.C.; Maximiano, D.H.; Canova, L.S.; Pontes, O.F.S.; Sabin, G.P.; Kaiser, S. Analysis of chemosensory markers in cigarette smoke from different tobacco varieties by GCXGC-TOFMS and chemometrics. Talanta 2019, 202, 74-89. [CrossRef] [PubMed]

27. Zhao, C.X.; Li, X.N.; Liang, Y.Z.; Fang, H.Z.; Huang, L.F.; Guo, F.Q. Comparative analysis of chemical components of essential oils from different samples of Rhododendron with the help of chemometrics methods. Chemom. Intell. Lab. Syst. 2006, 82, 218-228. [CrossRef]

28. Küçük, S.; Kürkçüoğlu, M.; Başer, K.H.C. Morphological, Indumentum and Chemical Characteristics and Analysis of the Volatile Components of the Flowers of Rhododendron ponticum L. subsp. ponticum (Ericaceae) of Turkish Origin. Rec. Nat. Prod. 2018, 12, 498-507.

29. Park, C.H.; Yeo, H.J.; Kim, N.S.; Park, Y.E.; Park, S.Y.; Kim, J.K.; Park, S.U. Metabolomic profiling of the white, violet, and red flowers of Rhododendron schlippenbachii Maxim. Molecules 2018, 23, 827. [CrossRef]

30. Purcaro, G.; Cordero, C.; Liberto, E.; Bicchi, C.; Conte, L.S. Toward a definition of blueprint of virgin olive oil by comprehensive two-dimensional gas chromatography. J. Chromatogr. A. 2014, 1334, 101-111. [CrossRef]

31. Jiang, M.; Kulsing, C.; Marriott, P.J. Comprehensive 2D gas chromatography-time-of-flight mass spectrometry with 2D retention indices for analysis of volatile compounds in frankincense (Boswellia papyrifera). Anal. Bioanal. Chem. 2018, 410, 3185-3196. [CrossRef]

32. Feng, S.; Huang, M.Y.; Crane, J.H.; Wang, Y. Characterization of key aroma-active compounds in lychee (Litchi chinensis Sonn.). J. Food Drug Anal. 2018, 26, 497-503. [CrossRef]

33. Mo, E.K.; Sung, C.K. Phenylethyl alcohol (PEA) application slows fungal growth and maintains aroma in strawberry. Postharvest Biol. Technol. 2007, 45, 234-239. [CrossRef]

34. An, K.J.; Liu, H.C.; Fu, M.Q.; Qian, M.C.; Yu, Y.S.; Wu, J.J.; Xiao, G.S.; Xu., Y.J. Identification of the cooked off-flavor in heat-sterilized lychee (Litchi chinensis Sonn.) juice by means of molecular sensory science. Food Chem. 2019, 301, 125282. [CrossRef] 
35. Gulati, A.; Ravindranath, S.D. Seasonal variations in quality of Kangra tea (Camellia sinensis (L) O Kuntze) in Himachal Pradesh. J. Sci. Food Agr. 1996, 71, 231-236. [CrossRef]

36. Zhu, J.C.; Chen, F.; Wang, L.Y.; Niu, Y.W.; Chen, H.X.; Wang, H.L.; Xiao, Z.B. Characterization of the key aroma volatile compounds in Cranberry (Vaccinium macrocarpon Ait.) using gas chromatography-olfactometry (GC-O) and odor activity value (OAV). J. Agr. Food Chem. 2016, 64, 4990-4999. [CrossRef]

37. Zhu, J.C.; Wang, L.Y.; Xiao, Z.B.; Niu, Y.W. Characterization of the key aroma compounds in mulberry fruits by application of gas chromatography-olfactometry (GC-O), odor activity value (OAV), gas chromatography-mass spectrometry (GC-MS) and flame photometric detection (FPD). Food Chem. 2018, 245, 775-785. [CrossRef]

38. Lv, H.P.; Zhong, Q.S.; Lin, Z.; Wang, L.; Tan, J.F.; Guo, L. Aroma characterisation of Pu-erh tea using headspace-solid phase microextraction combined with GC/MS and GC-olfactometry. Food Chem. 2012, 130, 1074-1081. [CrossRef]

39. Feng, Z.H.; Li, Y.F.; Li, M.; Wang, Y.J.; Zhang, L.; Wan, X.C.; Yang, X.G. Tea aroma formation from six model manufacturing processes. Food Chem. 2019, 285, 347-354. [CrossRef]

40. Silva, É.A.S.; Saboia, G.; Jorge, N.C.; Hoffmann, C.; dos Santos Isaias, R.M.; Soares, G.L.G.; Zini, C.A. Development of a HS-SPME-GC/MS protocol assisted by chemometric tools to study herbivore-induced volatiles in Myrcia splendens. Talanta 2017, 175, 9-20. [CrossRef]

41. Xiang, Z.M.; Chen, X.T.; Zhao, Z.J.; Xiao, X.; Guo, P.R.; Song, H.C.; Yang, X.; Huang, M.H. Analysis of volatile components in Dalbergia cochinchinensis Pierre by a comprehensive two-dimensional gas chromatography with mass spectrometry method using a solid-state modulator. J. Sep. Sci. 2018, 41, 1-8. [CrossRef]

42. Wang, C.C.; Zhang, W.J.; Li, H.D.; Mao, J.S.; Guo, C.Y.; Ding, R.Y.; Wang, Y.; Fang, L.P.; Chen, Z.L.; Yang, G.S. Analysis of Volatile Compounds in Pears by HS-SPME-GC $\times$ GC-TOFMS. Molecules 2019, 24, 1795. [CrossRef]

Sample Availability: Samples of the compounds are available from the authors.

(C) 2019 by the authors. Licensee MDPI, Basel, Switzerland. This article is an open access article distributed under the terms and conditions of the Creative Commons Attribution (CC BY) license (http://creativecommons.org/licenses/by/4.0/). 